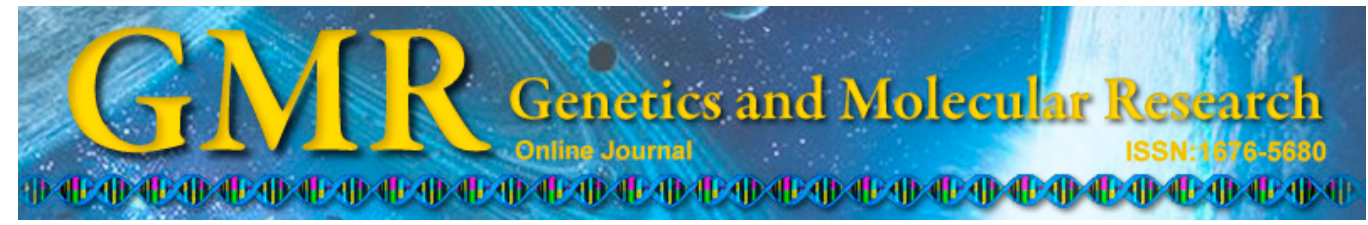

\title{
Association between single-nucleotide polymorphisms of fatty acid synthase gene and meat quality traits in Datong Yak (Bos grunniens)
}

\author{
M. Chu ${ }^{1,2 *}$, X.Y. Wu ${ }^{1,2 *}$, X. Guo ${ }^{1,2}$, J. Pei ${ }^{1,2}$, F. Jiao ${ }^{3}$, H.T. Fang ${ }^{3}$, \\ C.N. Liang ${ }^{1,2}$, X.Z. Ding, ${ }^{1,2}$, P.J. Bao ${ }^{1,2}$ and P. Yan $^{1,2}$ \\ ${ }^{1}$ Lanzhou Institute of Husbandry and Pharmaceutical Sciences, \\ Chinese Academy of Agricultural Science, Lanzhou, China \\ ${ }^{2}$ Key Laboratory of Yak Breeding Engineering of Gansu Province, \\ Lanzhou, China \\ ${ }^{3}$ Food and Drug Administration of Jinchang, Jinchang, China \\ *These authors contributed equally to this study. \\ Corresponding author: P. Yan \\ E-mail: pingyanlz@163.com
}

Genet. Mol. Res. 14 (1): 2617-2625 (2015)

Received April 3, 2014

Accepted October 2, 2014

Published March 30, 2015

DOI http://dx.doi.org/10.4238/2015.March.30.21

\begin{abstract}
Fatty acid synthase (FASN) is a key enzyme in fatty acid anabolism that plays an important role in the fat deposit of eukaryotic cells. Therefore, in this study, we detected 2 novel single-nucleotide polymorphisms (SNPs) in the FASN gene in 313 adult individuals of Datong yak using polymerase chain reaction-single strand conformation polymorphism and DNA sequencing techniques. SNP g.5477C $>$ T is located in intron 3 of $F A S N$, and 3 genotypes, $\mathrm{HH}, \mathrm{HG}$, and GG, were detected in this mutation site. SNP g.16930T $>$ A is located in exon 37 of $F A S N$, and 2 genotypes, EE and EF, were detected in this site. Association analysis of these 2 SNPs with meat quality traits showed that in SNP g.5477C>T, yaks with the HH genotype and HG genotype
\end{abstract}


had significantly higher intramuscular fat content than individuals with the GG genotype $(\mathrm{P}<0.01)$. In SNP g.16930T>A, yaks with the EE genotype also had significantly higher IMF content than individuals with the EF genotype $(\mathrm{P}<0.01)$. The results indicate that FASN may be used as a candidate gene affecting intramuscular fat content in Datong yaks.

Key words: Fatty acid synthase gene; Meat quality traits; Polymorphism; Yak

\section{INTRODUCTION}

Most fatty acids needed for animal body fat deposition originate from the de novo fatty acid synthesis, which requires fatty acid synthase (FASN) to catalyze the reaction between acetyl coenzyme A, malonyl-CoA, and nicotinamide adenine dinucleotide phosphate (Stuart et al., 1991; Chakravarty et al., 2004). FASN is thought to be a candidate gene in animal breeding for improving fat deposition and meat quality traits and plays a central role in lipogenesis in mammals (Roy et al., 2005; Zhang et al., 2008). The bovine FASN gene is located on chromosome 19 (Roy et al., 2001) and is 18,824 base pairs in length, including 42 exons and 41 introns. Reverse transcription-polymerase chain reaction (PCR) and Western blot analysis have shown that FASN expression in the brain, testis, and adipose tissue is higher than that in the liver and heart (Roy et al., 2005). Genetic variants of FASN gene have been reported to be associated with fat percentage in bovine milk (Roy et al., 2006). Five single-nucleotide polymorphisms (SNPs) in 3 different cattle populations have been identified, and association mapping results using these SNPs were associated with variation in fatty acid composition in adipose fat and milk fat (Morris et al., 2007).

Yak (Bos grunniens) is a domestic animal that lives on the Qinghai-Tibetan Plateau at altitudes between 2500 and $6000 \mathrm{~m}$. It is the primary source of meat, milk, and hair in this area of Tibet. Yak meat is high in protein and calories, yet low in fat, and is increasing in popularity because of its good taste. Moreover, yak meat is referred to as "green food" because yaks subsist on the alpine grassland without the pollution of modern industry (Guo et al., 2009). With the development of molecular genetics, genetic marker-assisted selection has been widely used in animal breeding (Yan et al., 2010). Thus, biological genetic marker technology is very important in yak breeding.

These findings suggest that the FASN gene plays an important role in fatty acid metabolism. Few studies of the FASN gene in yak have been reported. Therefore, the objective of this study was to detect potential SNPs in yak FASN gene and explore the associations between SNPs and meat quality traits in yak to select animals with better meat quality.

\section{MATERIAL AND METHODS}

\section{Animals}

During slaughter season (October-November), a total of 313 blood samples of adult (approximately 4 years old) Datong yaks were collected from domestic slaughter houses before slaughter. Several meat quality traits were measured in the longissimus dorsi muscle in a sample taken from the last rib. Intramuscular fat content (IMF) was measured using standard 
methodology (Honikel, 1998). Muscle $\mathrm{pH}$ was measured at $24 \mathrm{~h}$ post mortem (pH $24 \mathrm{~h}$ ) using a portable pH meter (Crison Instruments, Barcelona, Spain) (Korkeala et al., 1986). WarnerBratzler shear force was measured using the Texture Analyser Winopal (Ahnbeck, Germany) with a Warner-Bratzler blade (2.8 $\mathrm{mm}$ wide). Water holding capacity was estimated by centrifuging $1 \mathrm{~g}$ muscle placed on tissue paper inside a tube for $4 \mathrm{~min}$ at $1500 \mathrm{~g}$. The water remaining after centrifugation was quantified by drying the samples at $70^{\circ} \mathrm{C}$ overnight. Water holding capacity was calculated as: dried weight/initial weight $\mathrm{x} 100$. Cooked meat percentage was estimated as the percentage of the roasted sample weight (cooled for $30 \mathrm{~min}$, remove the meat samples stored at room temperature after cooling $15 \mathrm{~min}$ ). Genomic DNA was extracted using a genomic DNA isolation kit (Tiangene, Beijing, China) according to manufacturer instructions.

\section{Primer design and PCR amplification}

Five pairs of PCR primers (Table 1) were designed based on the bovine FASN gene (GenBank accession No. NC_000176). A 15- $\mu \mathrm{L}$ reaction volume included $1 \mu \mathrm{L}(50 \mathrm{ng} / \mu \mathrm{L})$ template, $7.5 \mu \mathrm{L} \mathrm{Taq}$ PCR MasterMix, 0.2 $\mu \mathrm{L}$ Taq DNA polymerase, $5.7 \mu \mathrm{LddH}_{2} \mathrm{O}$, and $0.3 \mu \mathrm{L}$ of each primer $(10 \mathrm{pM} / \mu \mathrm{L})$, performed in a Tpersonal thermocycler (Biometra, Goettingen, Germany) under the following conditions: $95^{\circ} \mathrm{C}$ for $5 \mathrm{~min}$ (preliminary denaturation), followed by 35 cycles of $94^{\circ} \mathrm{C}$ for $60 \mathrm{~s}$ (denaturation), primer annealing at $58.3^{\circ}$ and $57^{\circ} \mathrm{C}$ (corresponding to 2 primer pairs) for $35 \mathrm{~s}$, and $72^{\circ} \mathrm{C}$ for $50 \mathrm{~s}$, and a final extension at $72^{\circ} \mathrm{C}$ for $10 \mathrm{~min}$. PCR products were then electrophoresed on 1.5\% agarose gels using 1 X TBE buffer ( $89 \mathrm{mM}$ Tris, $89 \mathrm{mM}$ boric acid, $2 \mathrm{mM} \mathrm{EDTA} \mathrm{Na}_{2}$ ), containing $200 \mathrm{ng} / \mathrm{mL}$ ethidium bromide to detect the products.

\begin{tabular}{|c|c|c|c|}
\hline Primers & Sequence of primers & Size (bp) & Annealing temperature $\left({ }^{\circ} \mathrm{C}\right)$ \\
\hline$\overline{\mathrm{P} 1}$ & $\begin{array}{l}\text { F: GGTTTGACTTCTGCCTCCT } \\
\text { R: CCACTGCTCTCACCTGATG }\end{array}$ & 649 & 61 \\
\hline P2 & $\begin{array}{l}\text { F: CCAACCGCCTCTCCTTCTT } \\
\text { R: ACTCCCCTCTCTGGATGGC }\end{array}$ & 355 & 65 \\
\hline P3 & $\begin{array}{l}\text { F: TCGGCAAAGTGGTCATTCAG } \\
\text { R: CATTGTACTTGGGCTTGTTGA }\end{array}$ & 767 & 62.4 \\
\hline P4 & $\begin{array}{l}\text { F: GGGCACCTTAGGCTTGG } \\
\text { R: ACTCAGGGGTCTGGTTATCC }\end{array}$ & 365 & 59.3 \\
\hline P5 & $\begin{array}{l}\text { F: CTGAAGGGCACTAAAGACAAA } \\
\text { R: GGAGACCAGACTCGGAAGA }\end{array}$ & 256 & 57 \\
\hline
\end{tabular}

\section{Genotyping}

To screen for polymorphisms in the fragments analyzed, PCR amplifications were subjected to single-strand conformation polymorphism analysis. First, $4 \mu \mathrm{L}$ PCR products were mixed with $8 \mu \mathrm{L}$ loading dye $(98 \%$ formamide, $10 \mathrm{mM}$ EDTA, $0.025 \%$ bromophenol blue, and $0.025 \%$ xylene-cyanol) after denaturing at $98^{\circ} \mathrm{C}$ for $10 \mathrm{~min}$; the mixture was immediately placed on ice for $10 \mathrm{~min}$. Next, the mixture was loaded onto polyacrylamide gels and electrophoresed at $250 \mathrm{~V}$ for $10 \mathrm{~min}$ and then at $200 \mathrm{~V}$ for $2 \mathrm{~h}$ in $1 \mathrm{X}$ TBE buffer. The polyacrylamide gel was silver-stained with $0.1 \% \mathrm{AgNO}_{3}$ and visualized using $2 \% \mathrm{NaOH}$ (Lan et al., 2007). According to the PCR-single-strand conformation polymorphism band patterns observed using visual light, individual genotypes were defined (Qu et al., 2005). Amplifica- 
tions derived from the 3 allele standards were included on each gel for reference (Byun et al., 2008). Representative PCR products corresponding to different mutation types of homozygous individuals with different genotypes were sequenced. Forward and reverse reactions were both performed to rule out false-positives.

\section{Statistical analysis}

Genotypic frequency, allele frequency, Hardy-Weinberg equilibrium, gene homozygosity, gene heterozygosity (HE), effective allele numbers (NE), and polymorphism information content (PIC) were statistically analyzed using the method described by Nei and Roychoudhury (1974) and Nei and Li (1979). Associations between genotypes of SNPs in the FASN gene, 5 meat quality traits (water loss, cooked meat percentage, $\mathrm{PH}_{24}$, shear force, and IMF fat content), and genetic effects were analyzed using the general linear model procedure in the SPSS software (Version 18.0; SPSS, Inc., Chicago, IL, USA). The following model was used: $Y_{i j k}=\mu+S_{i}+N_{j}+E_{i j k}$, where $Y_{i j k}$ is the trait measured in yak, $\mu$ is the population mean, $S_{i}$ is the fixed effect of gender, $N_{j}$ is the fixed effect of genotype, and $E_{i j k}$ is random error. Significant differences between least-square means of different genotypes were determined using the Duncan multiple-range test, given that the trait was excluded from the model if its effect was not significant $(\mathrm{P}>0.05)$. The values are reported as least square means and standard error. $\mathrm{P}$ values of 0.05 were considered to be statistically significant.

\section{RESULTS}

\section{Genotype distribution and genetic diversity}

The PCR products obtained at the most suitable temperature were detected, and the amplification results were satisfactory (Figure 1A and B). The 2 target fragments of the gene were denatured; polymorphisms were identified by polyacrylamide gel electrophoresis (Figure $2 \mathrm{~A}$ and $\mathrm{B}$ ). For convenience, the 2 mutations were referred to as sequence variant 1 (SV1) and sequence variant 2 (SV2).
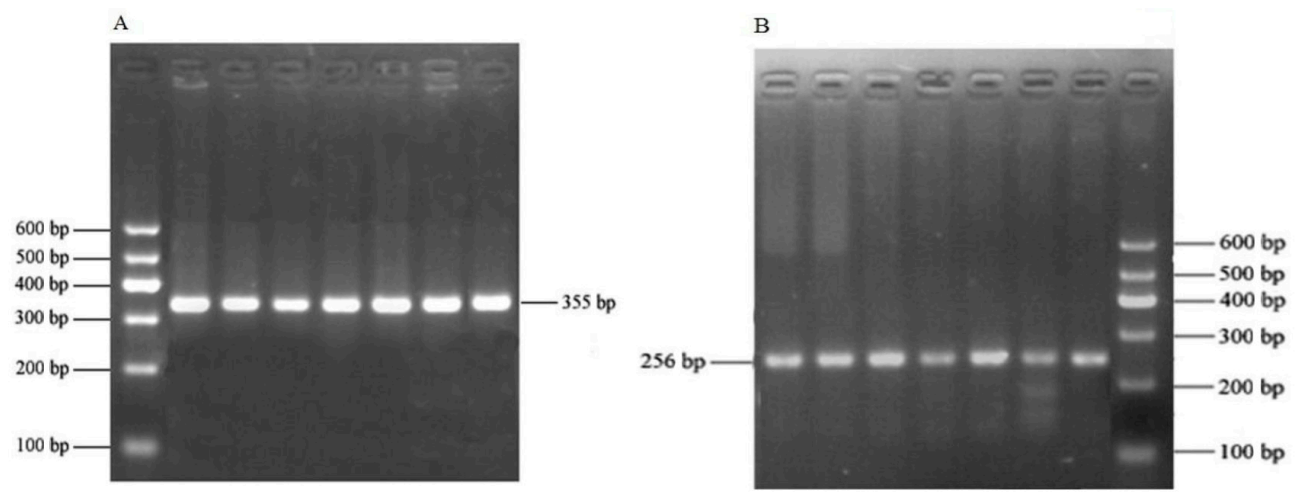

Figure 1. Detection of PCR products of SV1 (A) and SV2 (B). A. Lane $M=$ marker I (600; 500; 400; 300; 200; $100 \mathrm{bp})$; lanes $1-7=$ PCR products of SV1 $(355 \mathrm{bp})$. B. Lane $M=$ marker I $(600 ; 500 ; 400 ; 300 ; 200 ; 100 \mathrm{bp})$; lanes $1-7=$ PCR products of SV2 (256 bp). 
A

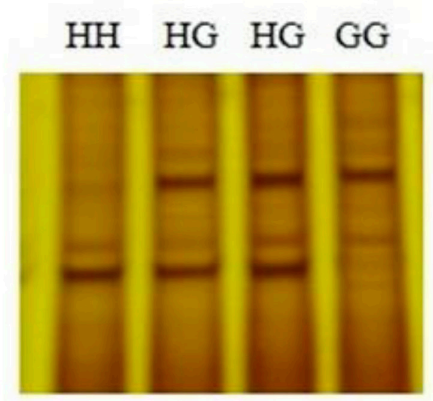

B

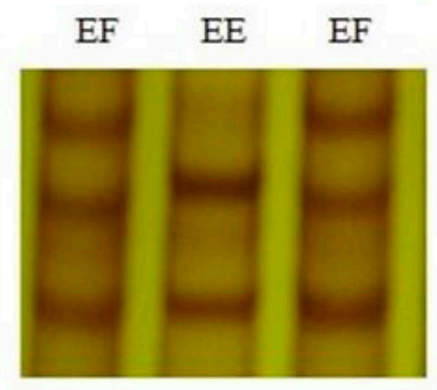

Figure 2. Electrophoresis pattern of PCR-SSCP of SV1 (A) and SV2 (B). A. Three genotypes HH, HG, and GG in SV1 locus. B. Three genotypes EE and EF in SV2 locus.

At the SV1 locus, 3 different genotypes ( $\mathrm{HH}, \mathrm{HG}$, and $\mathrm{GG}$ ) were identified in the Datong yak population. The frequencies of the 2 alleles were near and the heterozygote genotype $(\mathrm{HG})$ showed a high prevalence with a frequency of 0.645 . The genotypic frequencies of the SV1 locus in the Datong yak population were not in Hardy-Weinberg disequilibrium $(\mathrm{P}<$ 0.05 ) (Table 2). At the SV2 locus, only 2 genotypes (EE, EF) were identified. The frequency of allele $\mathrm{E}$ was dominant in the Datong yak population and EE genotype was more frequent than the EF genotype. The genotypic frequencies of the SV2 locus in Datong yak population agreed with Hardy-Weinberg disequilibrium $(\mathrm{P}>0.05)$ (Table 2).

Table 2. Genotypic frequencies at FASN gene for the SNPs in Datong yak.

\begin{tabular}{lcccccc}
\hline Locus & \multicolumn{3}{c}{ Genotype frequencies } & & \multicolumn{2}{c}{ Allele frequencies } \\
\cline { 2 - 4 } & HH & HG & GG & H & G \\
\hline SV1 & 0.232 & 0.610 & 0.158 & 0.537 & 0.463 & F \\
SV2 & EE & EF & FF & E & 0.900 & 0.100 \\
& 0.801 & 0.199 & 0 & 3.16 \\
\hline
\end{tabular}

$\chi^{2} 0.05=5.991, \chi^{2} 0.01=9.21$. The value of $\chi^{2}>5.991$ means $\mathrm{P}<0.05$, on the contrary, $\mathrm{P}>0.05$.

The allelic and genotypic frequencies, genetic diversity parameters $\left(H_{\mathrm{O}}, H_{\mathrm{E}}, N_{\mathrm{E}}\right.$, and PIC) of the 2 SNPs are shown in Table 3. According to the genetic diversity classification of PIC (PIC value $<0.25$, low polymorphism; $0.25<$ PIC value $<0.5$, intermediate polymorphism; and PIC value $>0.5$, high polymorphism), the SV1 locus possessed intermediate polymorphism and the SV2 locus possessed low polymorphism.

Table 3. Population genetic indices at the 2 loci ofthe $F A S N$ gene in Datong yak.

\begin{tabular}{lcccc}
\hline Locus & $H_{\mathrm{O}}$ & $H_{\mathrm{E}}$ & $N_{\mathrm{E}}$ & PIC \\
\hline SV1 & 0.502 & 0.498 & 1.992 & 0.375 \\
SV2 & 0.810 & 0.190 & 1.234 & 0.190 \\
\hline
\end{tabular}

$H_{\mathrm{O}}=$ gene homozygosity; $H_{\mathrm{E}}=$ gene heterozygosity; $N_{\mathrm{E}}=$ effective allele numbers; PIC $=$ polymorphism information content. PIC $>0.5$ means high diversity, $0.25<$ PIC $<0.5$ means moderate diversity, $\mathrm{PIC}<0.25$ means low diversity. 


\section{Sequence variants identified in the $F A S N$ gene}

Comparison between sequences of the bovine $F A S N$ gene and the pooled yak DNA samples revealed 2 SNPs, g.5477C $>$ T and g. 16930T $>$ A in intron 3 and exon 37, respectively (Figure 3A and B). The SNP g.16930T $>$ A was a synonymous mutation.

A

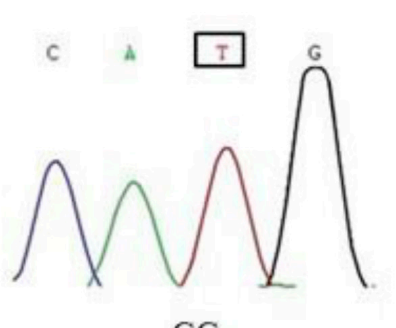

GG

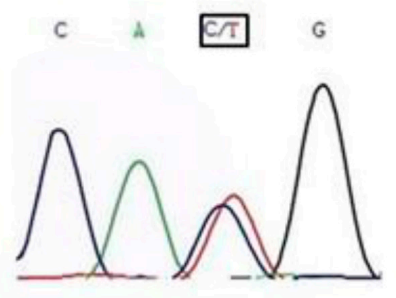

HG

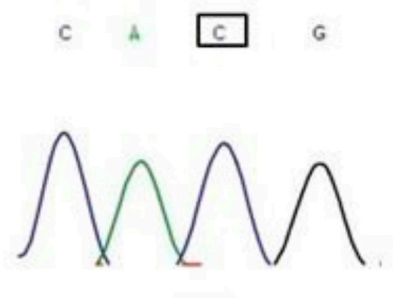

$\mathrm{HH}$

B

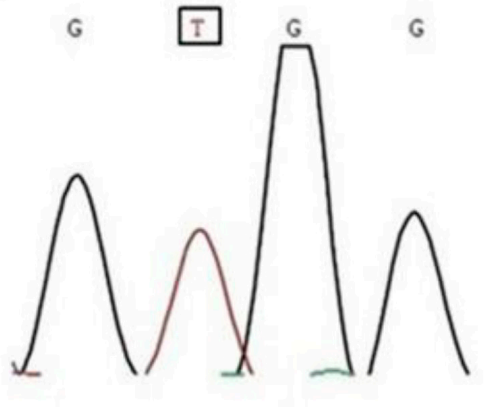

$\mathrm{EE}$

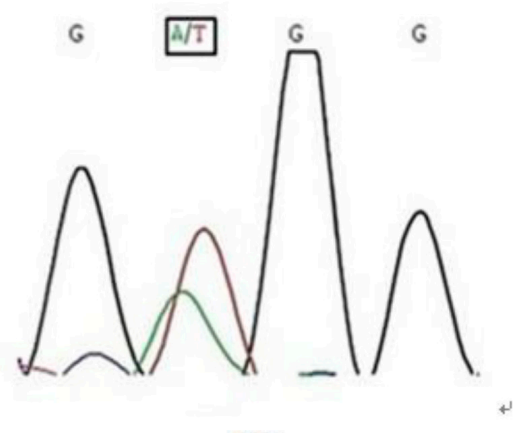

$\mathrm{EF}$

Figure 3. Sequences of SV1 (A) and SV2 (B). A. Sequences of 3 genotypes HH, HG, and GG in SV1 locus. B. Sequences of 2 genotypes EE and EF in SV2 locus.

\section{Association analysis}

The association analysis of the 2 mutations in the FASN gene of the Datong yak and meat quality traits are shown in Table 4. For the SV1 locus, the animals with genotype HH and $\mathrm{HG}$ showed significantly higher IMF content $(\mathrm{P}<0.01)$ than those with genotype GG, implying that the $\mathrm{H}$ is associated with fat content. For the SV2 locus, significant differences in IMF content $(\mathrm{P}<0.01)$ were observed between cattle with genotype $\mathrm{EE}$ and those with EF. The animals with genotype EE appeared to be superior in fat content compared to those with genotype EF. No significant differences were observed in $\mathrm{PH}_{24}$, water loss, cooked meat percentage, and shear force for these 2 mutations. The remaining records of meat quality traits showed no significant association $(\mathrm{P}>0.05)$. 
Table 4. Association between genotypes of the 2 SNPs of the FASN gene and meat quality traits in Datong yak.

\begin{tabular}{lcccccc}
\hline Locus & Genotype & Water loss (\%) & Cooked meat percentage (\%) & $\mathrm{pH}_{24}$ & Shear force $\mathrm{kg} / \mathrm{cm}^{2}$ & IMF content (\%) \\
\hline SV1 & HH & $28.12 \pm 0.38$ & $66.49 \pm 0.43$ & $5.37 \pm 0.06$ & $4.85 \pm 0.62$ & $1.99 \pm 0.64^{\mathrm{A}}$ \\
& HG & $27.96 \pm 0.55$ & $66.52 \pm 0.49$ & $5.37 \pm 0.04$ & $4.83 \pm 0.86$ & $1.97 \pm 0.54^{\mathrm{A}}$ \\
& GG & $27.95 \pm 0.48$ & $66.57 \pm 0.26$ & $5.34 \pm 0.06$ & $4.83 \pm 0.67$ & $1.88 \pm 0.52^{\mathrm{B}}$ \\
SV2 & EE & $28.12 \pm 0.73$ & $66.52 \pm 0.16$ & $5.37 \pm 0.08$ & $4.84 \pm 0.67$ & $1.96 \pm 0.62^{\mathrm{A}}$ \\
& EF & $28.19 \pm 0.52$ & $66.38 \pm 0.17$ & $5.36 \pm 0.06$ & $4.85 \pm 0.91$ & $1.88 \pm 0.63^{\mathrm{B}}$ \\
\hline
\end{tabular}

$\overline{\mathrm{A}, \mathrm{B}}$ Means with different superscript letters are highly significantly different $(\mathrm{P}<0.01) . \mathrm{pH}_{24}$ means $\mathrm{pH}$ value measured at $24 \mathrm{~h}$ after slaughtered.

\section{DISCUSSION}

As a central multifunctional enzyme responsible for de novo fatty acid biosynthesis, FASN is an important candidate gene affecting fat deposit and meat quality traits in animals. Numerous studies have been reported the effect of the FASN gene on fat acid in beef and milk. Morris et al. (2007) reported 5 SNPs in the FASN gene related to adipose fat and milk fat in 3 bovine breeds. Abe et al. (2009) and Matsuhashi et al. (2011) both reported SNPs in the FASN gene in Japanese Black beef; mutations were associated with fatty acid content of C18:0, C18:1, C14:0, C14:1, C16:0, and C16:1. Hou et al. (2011) reported the mutation g.16009 A/G in exon 34 of the FASN gene; this SNP had a significant effect on short-chain fatty acid content. Matsumoto et al. (2012) compared coding sequences of the $F A S N$ gene among 8 Holstein cattle. Thirteen SNPs were identified in Holstein cattle, and T1950A and W1955R affected milk fat content and C14 index. However, there have been no studies examining SNPs in the FASN gene in yak.

Meat quality is influenced by heredity, age, circumstances, and other factors. Heredity factors mainly refer to breed, while circumstance factors mainly refer to feeding conditions such as nutrition and temperature. To exclude the influence of different circumstance factors and age, we selected yaks of 1 breed (Datong yak) living in the same meadow of the same age of 4 years old as experimental animals. The quality of the beef was evaluated in the longissimus thoracis muscle because it is regarded as the most palatable cut (Matsuhashi et al., 2011).

In this study, 2 SNPs in the FASN gene were found in the Datong yak population, and affected meat quality traits. The first mutation was located in intron 3 , which was not in Hardy-Weinberg equilibrium. The second mutation was located in exon 37, which was in Hardy-Weinberg equilibrium. Allele $\mathrm{H}$ in intron 3 and allele $\mathrm{E}$ in exon 37 were dominant, and individuals with genotype $\mathrm{HH}$ and $\mathrm{HG}$ in the first mutation and of genotype EE in the second mutation performed better regarding IMF content than those with genotypes GG and EF. A previous study showed that higher IMF content indicates better tenderness and thus beef flavor. Yak meat has lower IMF content compared with cattle meat. Therefore, increasing the IMF content of yak meat is an effective method for improving meat flavor. Allele $\mathrm{H}$ in intron 3 and allele $\mathrm{E}$ in exon 37 both had a positive effect on IMF content in yak meat. In this study, no individuals with genotype FF were found in 313 yaks. Datong yak is a cultivated yak breed in China, and after nearly 30 years of artificial selections and cultivation, the yaks with better performance have already been selected for use as breeders. This mating mechanism disrupted the Hardy-Weinberg equilibrium of natural mating mechanism. As a result, alleles associated with high performances were maintained, while alleles associated with low performances were reduced. 
The results of this study as well as those of previous studies (Oh et al., 2012; Souza et al., 2012) suggest that $F A S N$ is an effective candidate gene that can be used as a DNA marker for improving IMF content through marker-assisted selection in yaks.

\section{CONCLUSIONS}

This study is the first to investigate the association between polymorphisms in the FASN gene and meat traits in Datong yak. Statistical results showed a significant relationship between the FASN polymorphisms and IMF content in Datong yak. In conclusion, the study indicated that genotyping of the $F A S N$ gene may be useful for selecting yaks with higher IMF content and thus improving the beef flavor.

\section{ACKNOWLEDGMENTS}

Research supported by the National Beef Cattle Industry Technology \& System (\#CARS-38), the Special Fund for Agro-Scientific Research in the Public Interest (\#201003061), the 'Five-twelfth' National Science and Technology Support Program (\#2012BAD13B05), the Recommend International Advanced Agricutural Science and Technology Plan (\#2013Z11), and the Fundamental Research Funds for Central Non-Profit Research Institutes (\#1610322014002).

\section{REFERENCES}

Abe T, Saburi J, Hasebe H, Nakagawa T, et al. (2009). Novel mutations of the FASN gene and their effect on fatty acid composition in Japanese Black beef. Biochem. Genet. 47: 397-411.

Byun SO, Fang Q, Zhou H and Hickford JG (2008). Rapid genotyping of the ovine ADRB3 gene by polymerase chain reaction-single-strand conformation polymorphism (PCR-SSCP). Mol. Cell. Probes 22: 69-70.

Chakravarty B, Gu Z, Chirala SS, Wakil SJ, et al. (2004). Human fatty acid synthase: structure and substrate selectivity of the thioesterase domain. Proc. Natl. Acad. Sci. U. S. A. 101: 15567-15572.

Guo X, Yan P, Liang CN, Pei J, et al. (2009). Developmental situations and countermeasures of Yak Industry in China. China Cattle Sci.35: 55-57.

Honikel KO (1998). Reference methods for the assessment of physical characteristics of meat. Meat Sci. 49: 447-457.

Hou YJ, Chang LL and Mao HB (2011). SNPs of FASN gene and their effects on fatty acids composition in Chinese Holstein. Chin. Cow 18: 1-4.

Korkeala H, Mäki-Petäys O, Alanko T and Sorvettula O (1986). Determination of pH in meat. Meat Sci. 18: 121-125.

Lan XY, Pan CY, Chen H, Zhang CL, et al. (2007). An AluI PCR-RFLP detecting a silent allele at the goat POU1F1 locus and its association with production traits. Small Ruminant Res. 73: 8-12.

Matsuhashi T, Maruyama S, Uemoto Y, Kobayashi N, et al. (2011). Effects of bovine fatty acid synthase, stearoylcoenzyme A desaturase, sterol regulatory element-binding protein 1, and growth hormone gene polymorphisms on fatty acid composition and carcass traits in Japanese Black cattle. J. Anim. Sci. 89: 12-22.

Matsumoto H, Inada S, Kobayashi E, Abe T, et al. (2012). Identification of SNPs in the FASN gene and their effect on fatty acid milk composition in Holstein cattle. Livestock Sci. 144: 281-284.

Nei M and Li WH (1979). Mathematical model for studying genetic variation in terms of restriction endonucleases. Proc. Natl. Acad. Sci. U. S. A. 76: 5269-5273.

Morris CA, Cullen NG, Glass BC, Hyndman DL, et al. (2007). Fatty acid synthase effects on bovine adipose fat and milk fat. Mamm. Genome 18: 64-74.

Nei M and Roychoudhury AK (1974). Sampling variances of heterozygosity and genetic distance. Genetics 76: 379-390.

Oh D, Lee Y, La B, Yeo J, et al. (2012). Fatty acid composition of beef is associated with exonic nucleotide variants of the gene encoding FASN. Mol. Biol. Rep. 39: 4083-4090.

Qu L, Li X, Wu G and Yang N (2005). Efficient and sensitive method of DNA silver staining in polyacrylamide gels. 
Electrophoresis 26: 99-101.

Roy R, Gautier M, Hayes H, Laurent P, et al. (2001). Assignment of the fatty acid synthase (FASN) gene to bovine chromosome $19\left(19 \mathrm{q}_{22}\right)$ by in situ hybridization and confirmation by somatic ce11 hybrid mapping. Cytogenet. Cell Genet. 93: 141-142.

Roy R, Taourit S, Zaragoza P, Eggen A, et al. (2005). Genomic structure and alternative transcript of bovine fatty acid synthase gene (FASN): comparative analysis of the FASN gene between monogastric and ruminant species. Cytogenet. Genome Res. 111: 65-73.

Roy R, Ordovas L, Zaragoza P, Romero A, et al. (2006). Association of polymorphisms in the bovine FASN gene with milk-fat content. Anim. Genet. 37: 215-218.

Souza FR, Chiquitelli MG, da Fonseca LF, Cardoso DF, et al. (2012). Associations of FASN gene polymorphisms with economical traits in Nellore cattle (Bos primigenius indicus). Mol. Biol. Rep. 39: 10097-10104.

Stuart S, Andrzej W and Anil KJ (1991). Structural and functional organization of the animal fatty acid synthase. Eur. J. Biochem. 198: 571-579.

Yan L, Lin JD, Zhang XJ and Zhang Y (2010). Application of single nucleotide polymorphism in breeding of pig. China Anim. Husbandry Vet. Med. 37: 94-98.

Zhang S, Knight TJ, Reecy JM and Beitz DC (2008). DNA polymorphisms in bovine fatty acid synthase are associated with beef fatty acid composition. Anim. Genet. 39: 62-70. 